\title{
Fire Design: Direct Comparison Between Fire Curves. The Case Study of a Nursery
}

\author{
Mara Lombardi, Giuliano Rossi, Nicolò Sciarretta and Nino Oranges \\ Department Ingegneria Chimica Materiali Ambiente, \\ Faculty of Civil and Industrial Engineering, Sapienza University di Roma, Rome, Italy
}

Received 2013-07-01, Revised 2013-09-02; Accepted 2013-09-06

\begin{abstract}
According to fire safety engineering, the present study analyzes fire design settings for simulation of fire in a nursery and proposes to compare simulations developed with a natural fire curve and nominal fire curve. Comparative analysis was developed according to thermo-fluid dynamic parameters that are relevant to the safety of the exposed and for the representative period of the danger flow to the exposed, which are mainly children between 0 and 3 years of age, helpless under ordinary conditions and even more so in case of emergency. Defined conditions of structure and ventilation, Two fire simulations, differentiated by fire curve, have been implemented: First simulation: the parameters have been derived from the simulation of a fire, characterized by analytic function of Heat Release Rate (HRR) Second simulation: the HRR function was obtained ex post by making a simulation of natural fire in realistically furnished room by imposing a minimum effective primer. The simulated HRR curve, appropriately linearized, allows to estimate a Likely Fire Curve (LFC). The simulations have been developed for a time of about 15 min, starting from the ignition of fire whereas the flow of the danger is serious for exposed mainly in this first phase of fire. The comparison between the parameters of fire involved the Temperature-Time Curve and HRR-Time Curve of both simulations and the ISO 834 Curve, which is a consolidated benchmark in Fire Safety Engineering (FSE). The nominal curves have been introduced for the purpose of checking whether the structural strength and integrity: the adoption of these curves in the fire safety engineering was made by analogy, on the assumption that the phenomena of major intensity, that these curves represent, ensure a safe approach on the choice of the fire design. The study showed indeed that the analytical curve, adopted in order to verify the structural strength, produces fields of both temperature and toxic concentrations lower than those obtained with the full simulation of the natural fire in order to the phases of ignition and growth, that is, in the step that requires activation of self rescue and emergency management. This result shows that taking compliance criterion, implicitly included in the analytical curves of fire, does not have the safe requirement typical of a protection approach. The advantage in taking natural fire simulations is evident in order to derive a Likely Fire Curve that for the purposes of both Thermo-Fluid Dynamics (TFD) and exodus simulation constitutes, as shown in the specific case study of nursery, a thermo-chemical stress more appropriate for the study of the safety of exposed and in the case of fire more serious.
\end{abstract}

Keywords: Fire Curves, Fire Design, Fire Safety Engineering (FSE), Nursery, Self Rescue

\section{INTRODUCTION}

The increase in computational power of recent years has involved the application of simulation software also to field of fire engineering, allowing the progress of research and innovative professional application, known as "Fire Safety Engineering".
Simultaneously the fire fighting technical regulation has met a gradual transition from prescriptive to performance based approach rules, giving to researcher/expert, through the use of simulative techniques, the require of verifying the expected performance related to fire strength of structure and/or self rescue of exposed.

Corresponding Author: Mara Lombardi, Department Ingegneria Chimica Materiali Ambiente, Faculty of Civil and Industrial Engineering, Sapienza University di Roma, Rome, Italy 
The consolidated compliance methodology is based on the definitions of regulations in the Eurocode (2004)

The check is constituted by the following steps:

- Definition of structural elements exposed to fire stress

- Selection of fires design

- Assessment of safety conditions (self-rescue or external rescue) of exposed to danger flow

- Assessment of the durability of the structural elements exposed to the fire (with reference to the structural strength and integrity)

The choice of fire design can be based on the expert use of natural fire curves or based on selection of a nominal fire curve from those available in literature and validated by the assumptions in technical rules.

The fire curve must be selected according to actual fire conditions, with reference to combustible material and to ventilation results, which determine the time trend of the combustion characteristic parameters (ignition, growth, fully developed, decay phases).

The nominal fire curves are divided into two main groups: HRR-Time curves and Temperature-Time curves.
The following Fig. 1 shows the performance of an exemplifying group of Temperature-Time curves, as derived from ISO 13387 (ISO, 1999b).

The simulations have been studied using Fire Dynamics Simulator (FDS) that is a Computational Fluid Dynamics (CFD) model of fire-driven fluid flow. The software solves numerically a form of the Navier-Stokes equations appropriate for low-speed, thermally-driven flow, with an emphasis on smoke and heat transport from fires.

Smoke View (SMV) is a visualization program that is used to display the output of FDS simulations.

FDS is free software developed by the National Institute of Standards and Technology (NIST) of the United States Department of Commerce (McGrattan et al., 2007).

\subsection{Case Study: Description of Simulation Layout}

The simulated domain is a multi-activity room typical of the nursery.

This domain, that includes the multi-activity room, has specified overall dimensions equal to: $6.0[\mathrm{~m}] \times 6.0$ $[\mathrm{m}] \times 3.6[\mathrm{~m}]$.

Squared room has dimensions equal to: $5.0[\mathrm{~m}] \times 5.0$ $[\mathrm{m}] \times 3.2[\mathrm{~m}]$, walls thickness is equal to $0.2[\mathrm{~m}]$.

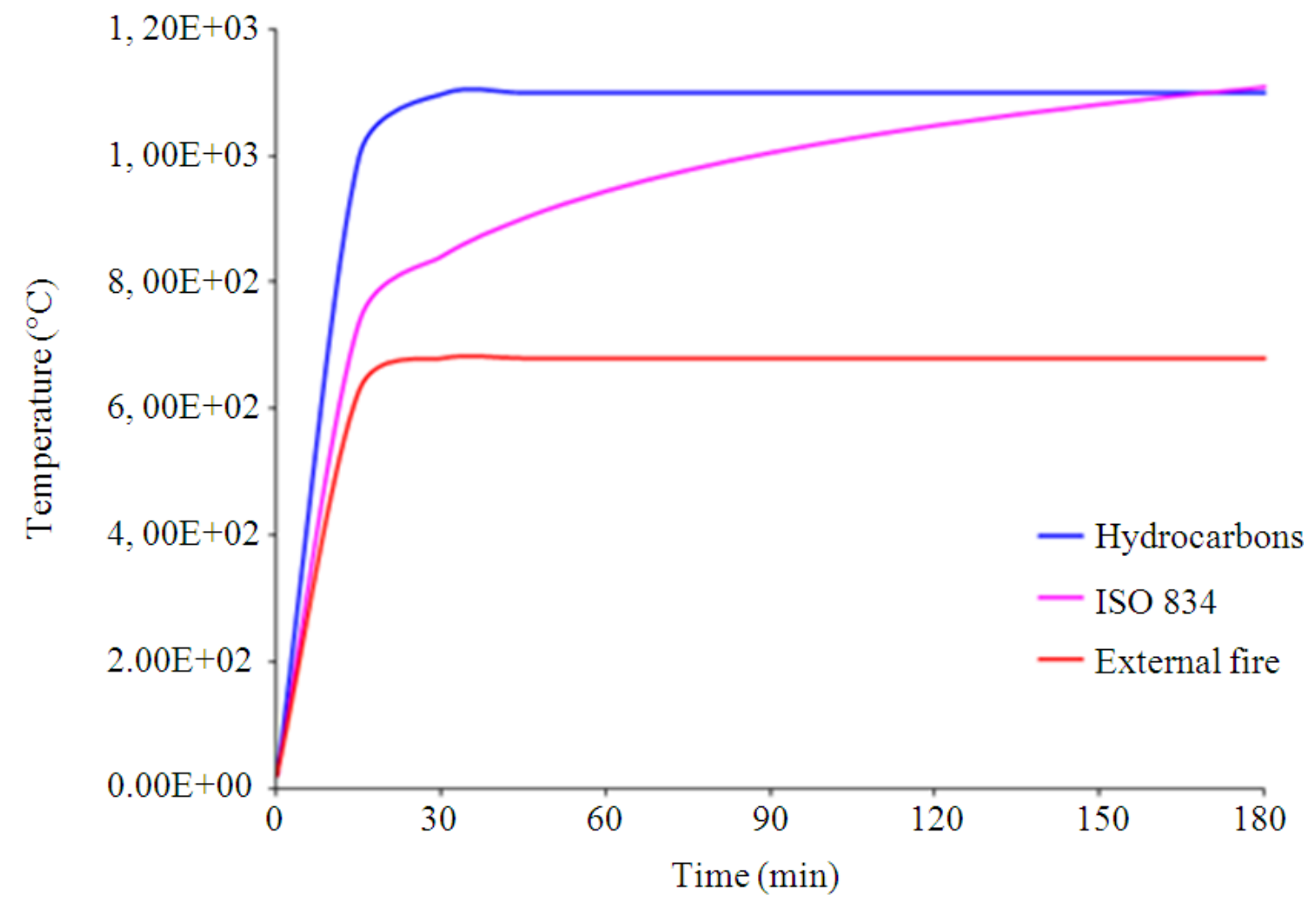

Fig. 1. ISO 13387 Temperature-Time Curves (ISO, 1999a) 
Two windows, located on adjacent walls, are measuring $1.0[\mathrm{~m}] \times 1.0[\mathrm{~m}]$. The door, located on a windowless wall, measures $0.8[\mathrm{~m}] \times 2.0[\mathrm{~m}]$ :

- The mesh of domain consist in 1036800 cubic cells of side equal to $0.05[\mathrm{~m}]$

- The evaluations were carried out considering fully open windows and door, the total area of ventilation is equal to 3.60 [m2] (14.4\% of floor surface) in order to ensuring stoichiometric combustion

\subsection{Analytic Fire Curve (AFC)}

The study of the analytical fire curve for the definition of the basic parameters which characterize the heat release curve has been developed adopting the Thomas' methods (SFPE, 2002).

The HRR curve presents a step of ignition (incipient phase) characterized by fire growth factor $(\alpha)$ equal to 0.01111 [KJS-3]), the subsequent step of a fully developed fire starts after $928 \mathrm{sec}$ and ends at 1823.5 sec, when conventionally has been consumed $70 \%$ of the available combustible material Eurocode (2004). The fire ends in $2426 \mathrm{~s}$.

The total fire load due to the different combustible materials was calculated using the following Equation (1) (Babrauskas, 2008):

$$
\mathrm{q}_{\mathrm{f}}=\sum_{\mathrm{i}=1}^{\mathrm{n}} \mathrm{g}_{\mathrm{i}} \cdot \mathrm{H}_{\mathrm{i}} \cdot \mathrm{m}_{\mathrm{i}} \cdot \psi_{\mathrm{i}}[\mathrm{MJ}]
$$

Where:

gi $=$ Mass of the $\mathrm{i}^{\text {th }}$ combustible material $[\mathrm{kg}]$

$\mathrm{Hi}=$ Lower heating value of the ith combustible material $[\mathrm{MJ} / \mathrm{kg}]$

$\mathrm{I}=$ Factor of combustion of the nth combustible material equal to 0.80

$\Psi_{\mathrm{I}}=$ Limiting factor of participation to the combustion equal to 1

The characteristic values for the evaluation of the HRR Analytical Fire Curve (HRRAFC) are shown below (Richard et al., 1999) Equation (2 and 3):

$$
\begin{aligned}
& \mathrm{O}_{\mathrm{V}}=0.042754\left[\mathrm{~m}^{0.5}\right](\text { Opening Ventilation }) \\
& \mathrm{HRR}_{\mathrm{Fmin}}=7.8 \times\left(\mathrm{A}_{\mathrm{T}}-\mathrm{A}_{\mathrm{Veq}}\right)+ \\
& 378 \mathrm{~A}_{\mathrm{Veq}} \times \mathrm{h}_{\text {Veq }}^{0.5}=3343[\mathrm{~kW}] \\
& \mathrm{t}_{\mathrm{F}}=549[\mathrm{~s}](\text { flash }- \text { over time })
\end{aligned}
$$

$$
\mathrm{HRR}_{\max }=3.15 \times\left(1-\mathrm{e}^{\frac{-0.036}{\mathrm{O}_{\mathrm{v}}}}\right) \mathrm{A}_{\mathrm{v}}\left(\mathrm{h}_{\mathrm{veq}} \frac{\mathrm{W}}{\mathrm{D}}\right)^{\frac{1}{2}}=9577.2[\mathrm{~kW}]
$$

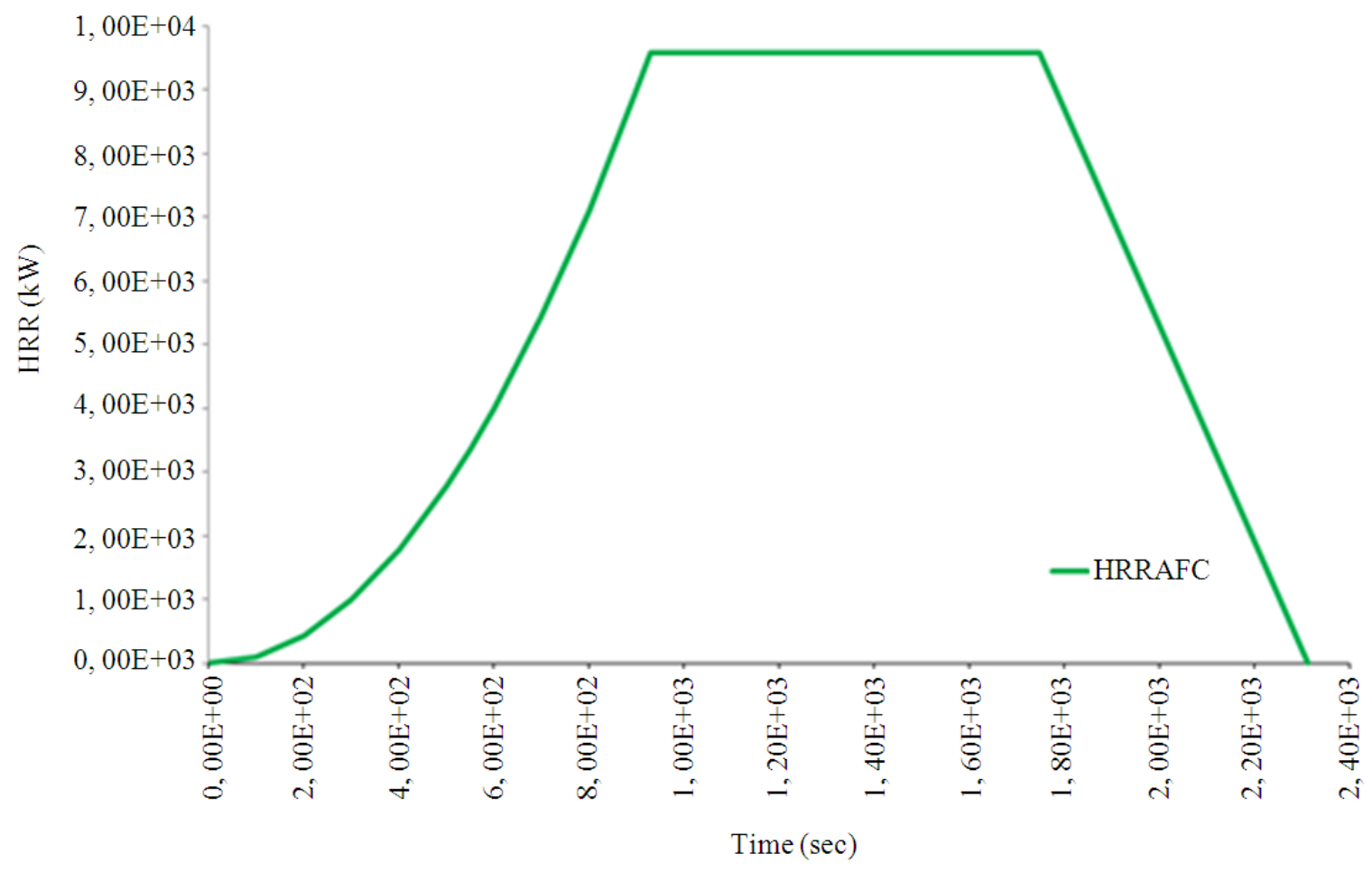

Fig. 2. HRR analytical fire curve 


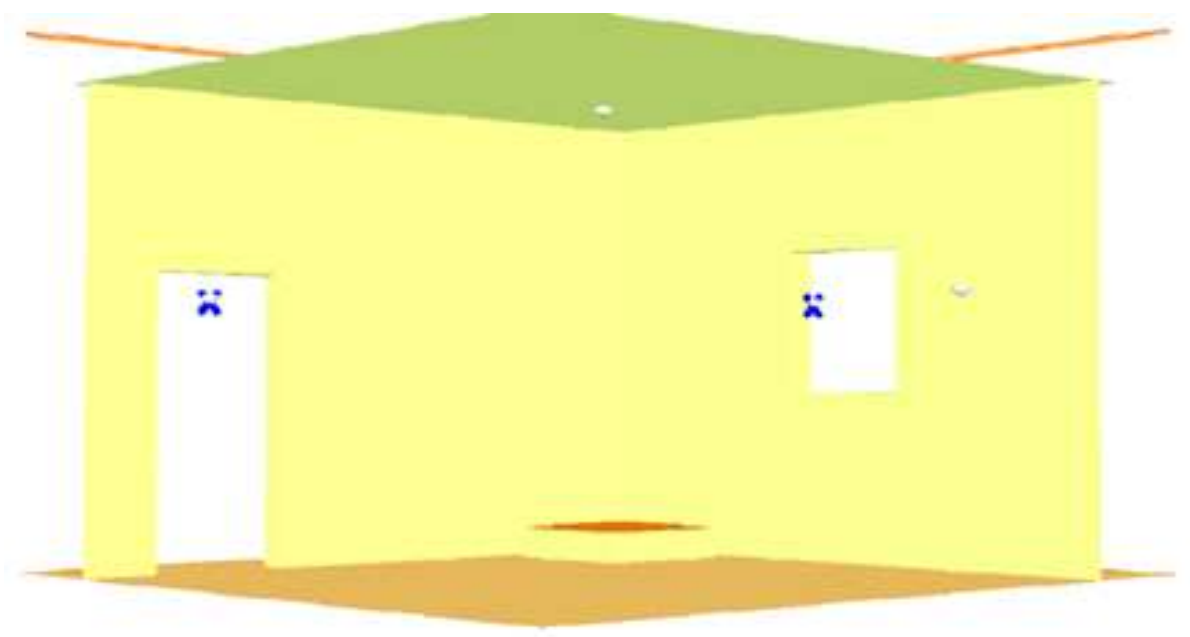

Fig. 3. Room layout-orange vent "Burner"

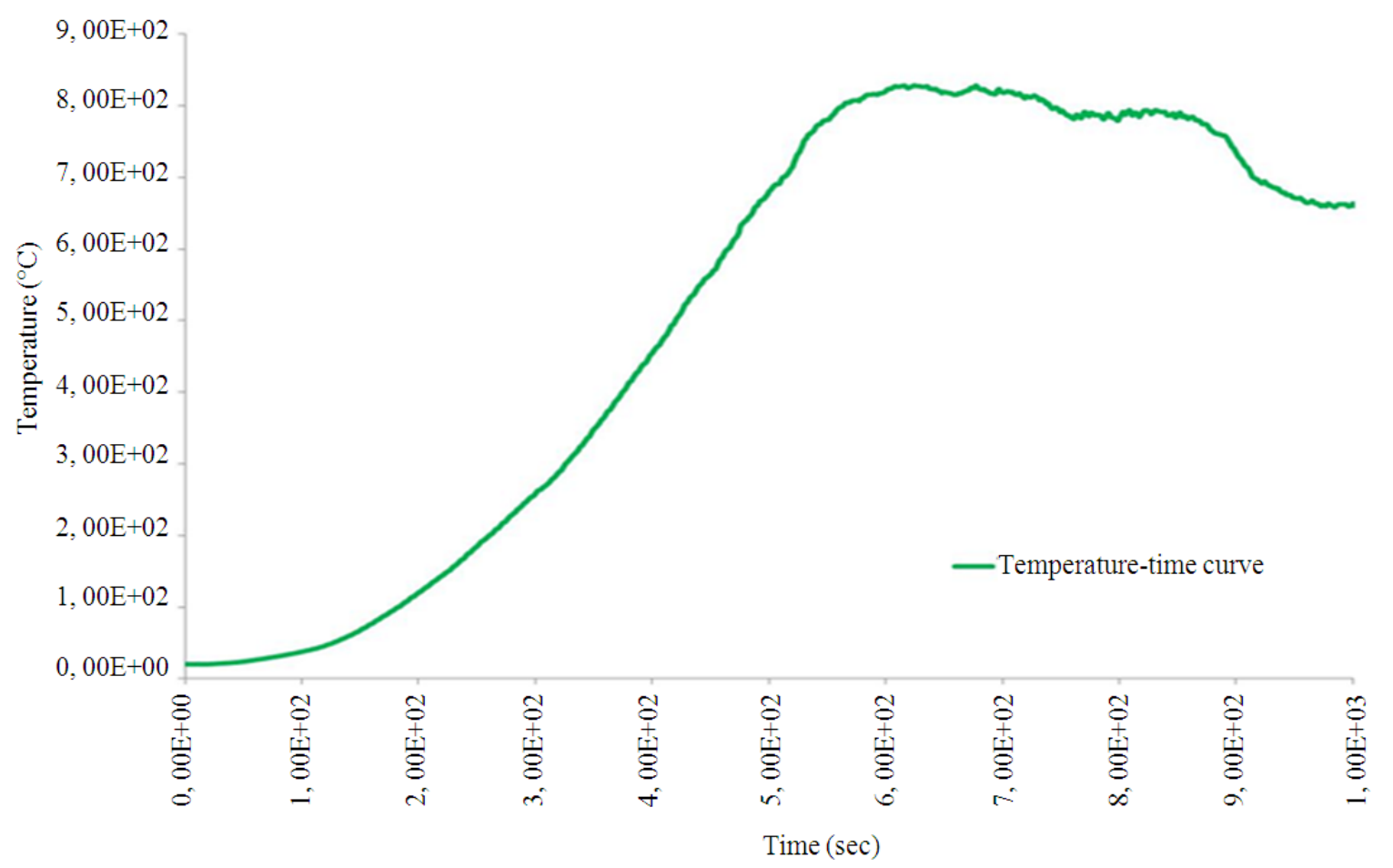

Fig. 4. Temperature-time curve from HRRAFC

The Fig. 2 draws resulting $\mathrm{HRR}_{\mathrm{AFC}}$ (Babrauskas, 2008).

\subsection{Comparison of Analytical Evaluation and FDS Simulations}

The fire simulation was developed by imposing in FDS setting file the analytical HRRAFC (Fig. 2), as thermal parameter of a burner element included in computational domain of thermo-fluid dynamics simulation orange vent in (Fig. 3).
The Temperature-Time Curve, output of simulation, is below in Fig. 4.

The Temperature-Time Curve shows a preliminary phase characterized by the growth factor pseudo linear until it takes the maximum value equal to $690^{\circ} \mathrm{C}$ in an approximately time of $630 \mathrm{sec}$, a stationary phase with a nearly constant temperature of approximate time equal to $200 \mathrm{sec}$, a final cooling-off phase with decreasing trend of temperature. 


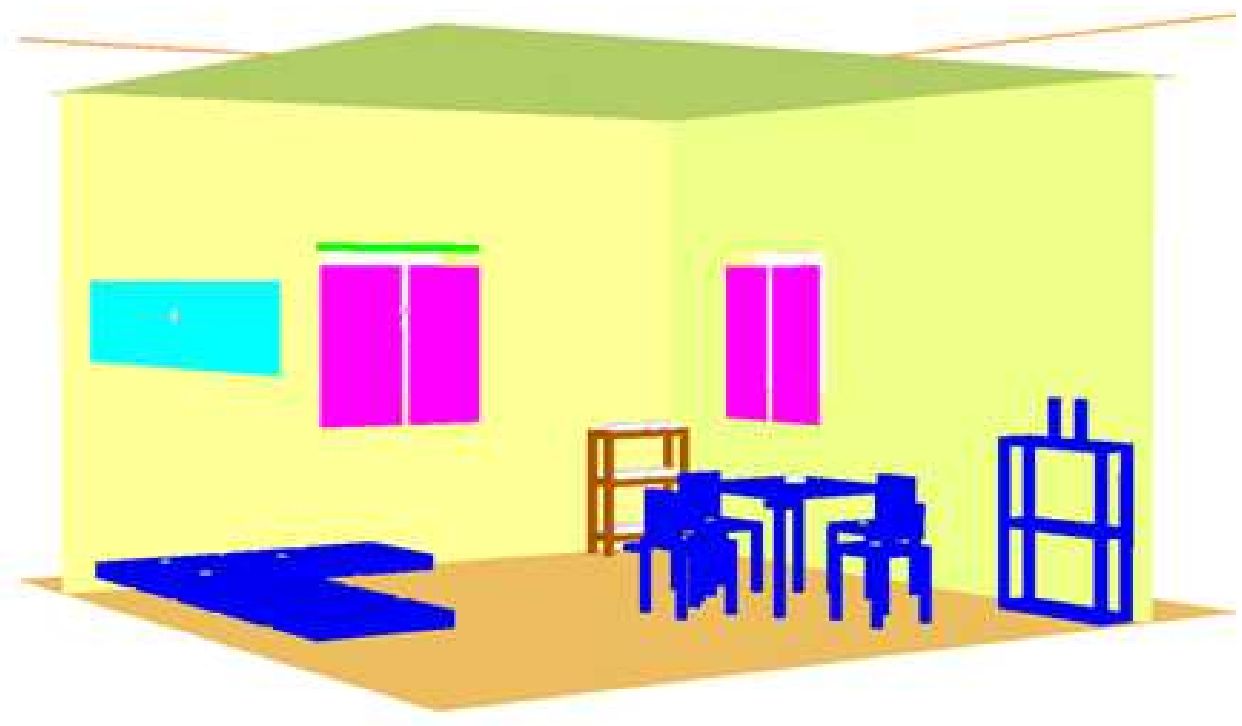

Fig. 5. Furnished of simulated room

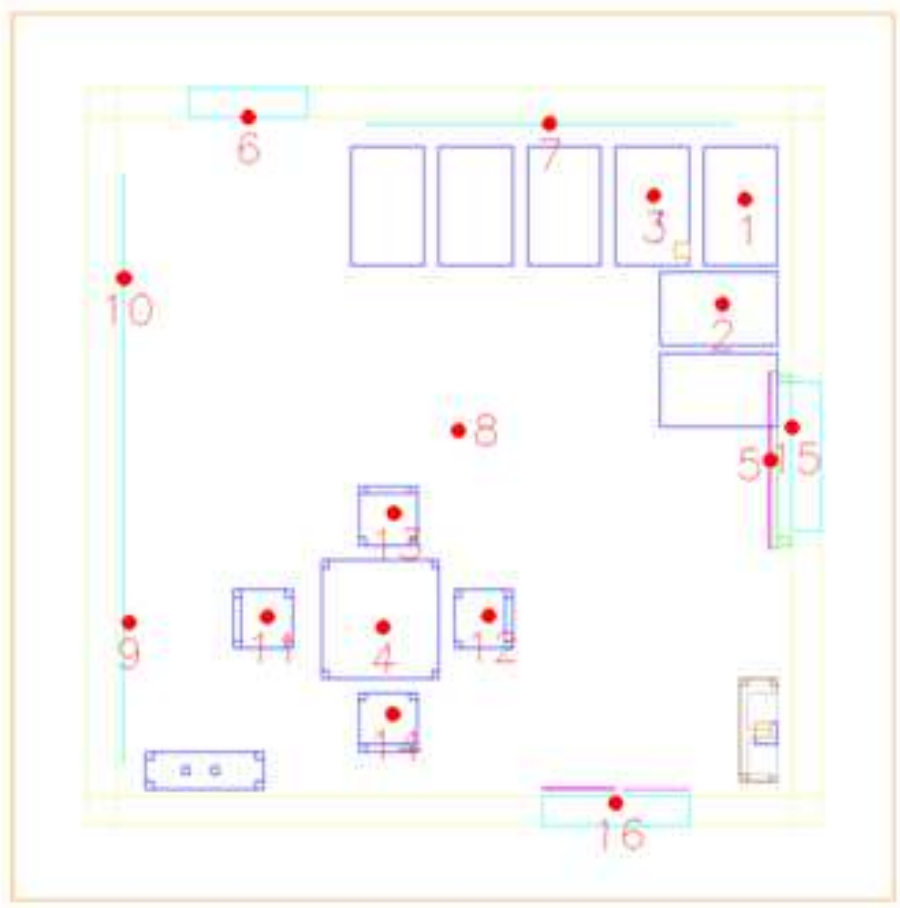

Fig. 6. Room layout, ventilation openings, furnishings and probes

\subsection{Fire simulation-Natural Curve}

Simulation domain has been modelled, in terms of geometry and boundary conditions, identically to the case study developed with the analytical curve.

The room was then furnished according to specific real use.

Figure 5 shows the simulated room that has the following combustible furnishings:
- 7 mats (overall dimensions: $0.8[\mathrm{~m}] \times 0.5[\mathrm{~m}] \times 0.1$ [m]-material: polyurethane)

- Table 1 (overall dimensions: $0.8[\mathrm{~m}] \times 0.8[\mathrm{~m}] \times 0.05$ [m] (table top) and $0.05[\mathrm{~m}] \times 0.05[\mathrm{~m}] \times 0.7[\mathrm{~m}]$ (legs) material: wooden)

- 4 chairs (overall dimensions: $0.4[\mathrm{~m}] \times 0.4[\mathrm{~m}] \times 0.05$ [m] (chair seat) and $0.05[\mathrm{~m}] \times 0.05[\mathrm{~m}] \times 0.4[\mathrm{~m}]$ (legs)-material: wooden) 
- 1 open-shelf (overall dimensions: $0.25[\mathrm{~m}] \times 0.70[$ $\mathrm{m}] \times 0.05 \quad[\mathrm{~m}] \quad(3$ shelves $)$ and $0.05 \quad[\mathrm{~m}] \times 0.05$ $[\mathrm{m}] \times 1.00[\mathrm{~m}]$ (4 posts)-material: wooden)

- 1 open-shelf (overall dimensions: $0.25[\mathrm{~m}] \times 0.60$ $[\mathrm{m}] \times 0.05 \quad[\mathrm{~m}] \quad(3$ shelves $)$ and $0.05 \quad[\mathrm{~m}] \times 0.05$ $[\mathrm{m}] \times 0.90[\mathrm{~m}]$ (4 posts)-material: wooden)

- 1 window curtain support structure (overall dimensions: $1.2[\mathrm{~m}] \times 0.05[\mathrm{~m}] \times 0.05[\mathrm{~m}]$ and 0.05 $[\mathrm{m}] \times 0.05[\mathrm{~m}] \times 0.1[\mathrm{~m}](2$ supports $)$-material: wooden $)$

- 6 reams (dimensions: $0.2[\mathrm{~m}] \times 0.25[\mathrm{~m}] \times 0.05[\mathrm{~m}]-$ material: paper)

- 2 posters on the non-windows walls (sizes: 1 poster ( $4.0[\mathrm{~m}] \times 0.5[\mathrm{~m}], 1$ poster $(2.5[\mathrm{~m}] \times 0.5[\mathrm{~m}]-$ material: paper)

- 2 bottles (material: plastic)

- 2 curtains (dimensions: $0.45[\mathrm{~m}] \times 1.1 \quad[\mathrm{~m}] \times 0.002$ [m]-material: acrylic fiber)

In order to monitor the fire parameters trend, in computational domain distributed thermocouples, as shown in Fig. 6, were included.

The temperature probes were placed near ventilation openings of the room (door and windows, probes $\mathrm{n}^{\circ} 6$ 15-16), near combustible objects (mats, probes $\mathrm{n}^{\circ} 1-2-3$, posters, probes $n^{\circ} 09-07-10$, curtains, probe $n^{\circ} 5$, table and chairs, probes $\left.\mathrm{n}^{\circ} 4-11-12-13-14\right)$ and in midpoint of the ceiling (probe No. 8) (Fig. 7).

The primer of combustible material is obtained by activating a radiating plate, located at the bottom of mat, characterized by a minimum temperature required for primer: the purpose is to enable a process of resistant combustion (as to achieve condition of ignition and fully development) so that the plate does not affects the parameters of the activated reaction, thus performing the conditions of natural ignition (as may be the case, for example, of primers due to cigarette butts or shorted electrical devices).

The characteristics of the primer were obtained through specific simulations to derive minimum temperature and minimum time needed to stable ignition of the combustible material, having imposed a starting minimum surface of primer equal to $0.05[\mathrm{~m}] \times 0.05[\mathrm{~m}]$.

By this analysis, the operating characteristics of the plate have been derived:

- Dimensions: $0.10[\mathrm{~m}] \times 0.10[\mathrm{~m}]$

- Temperature: $1500\left[{ }^{\circ} \mathrm{C}\right]$

- Operatine time: 150 [s]

The primed material at time $\mathrm{t}=0$ is polyurethane.

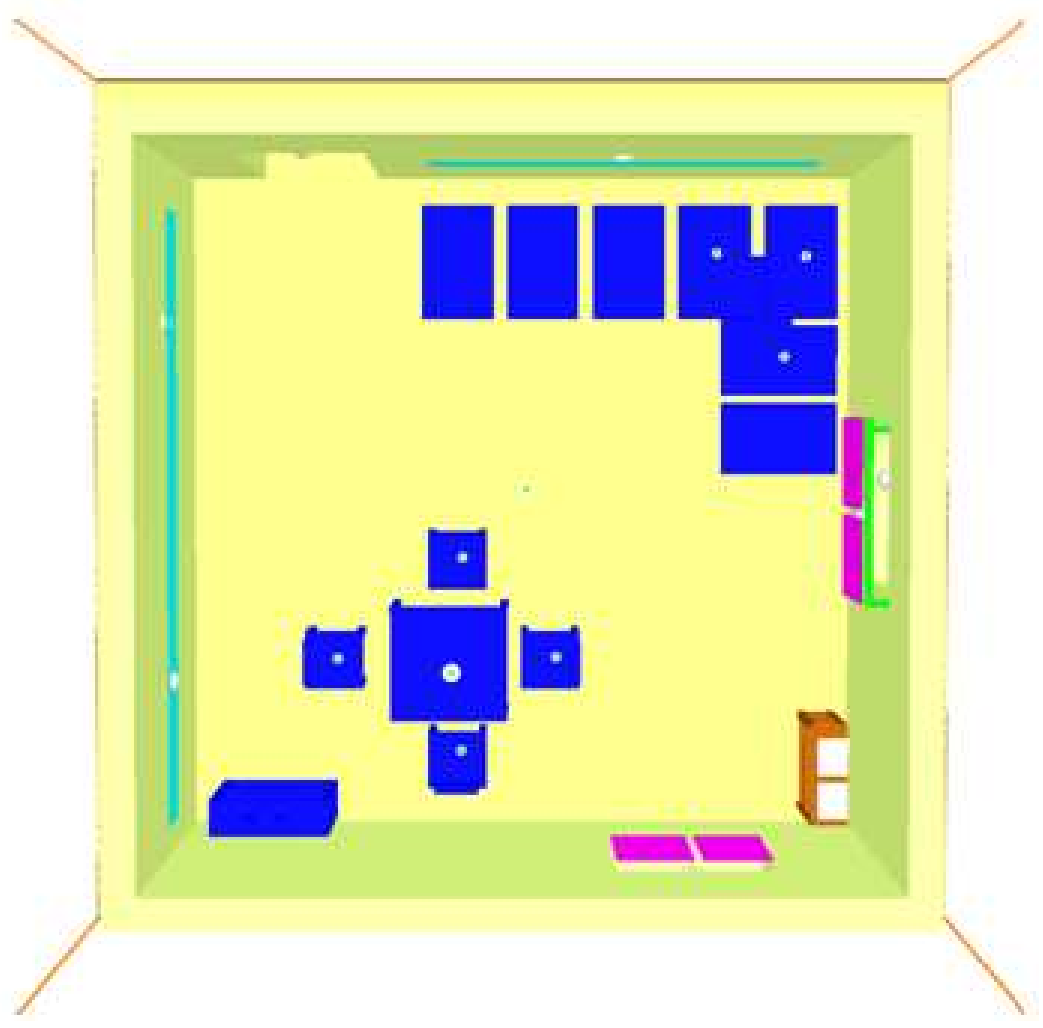

Fig. 7. Smokeview's layout 


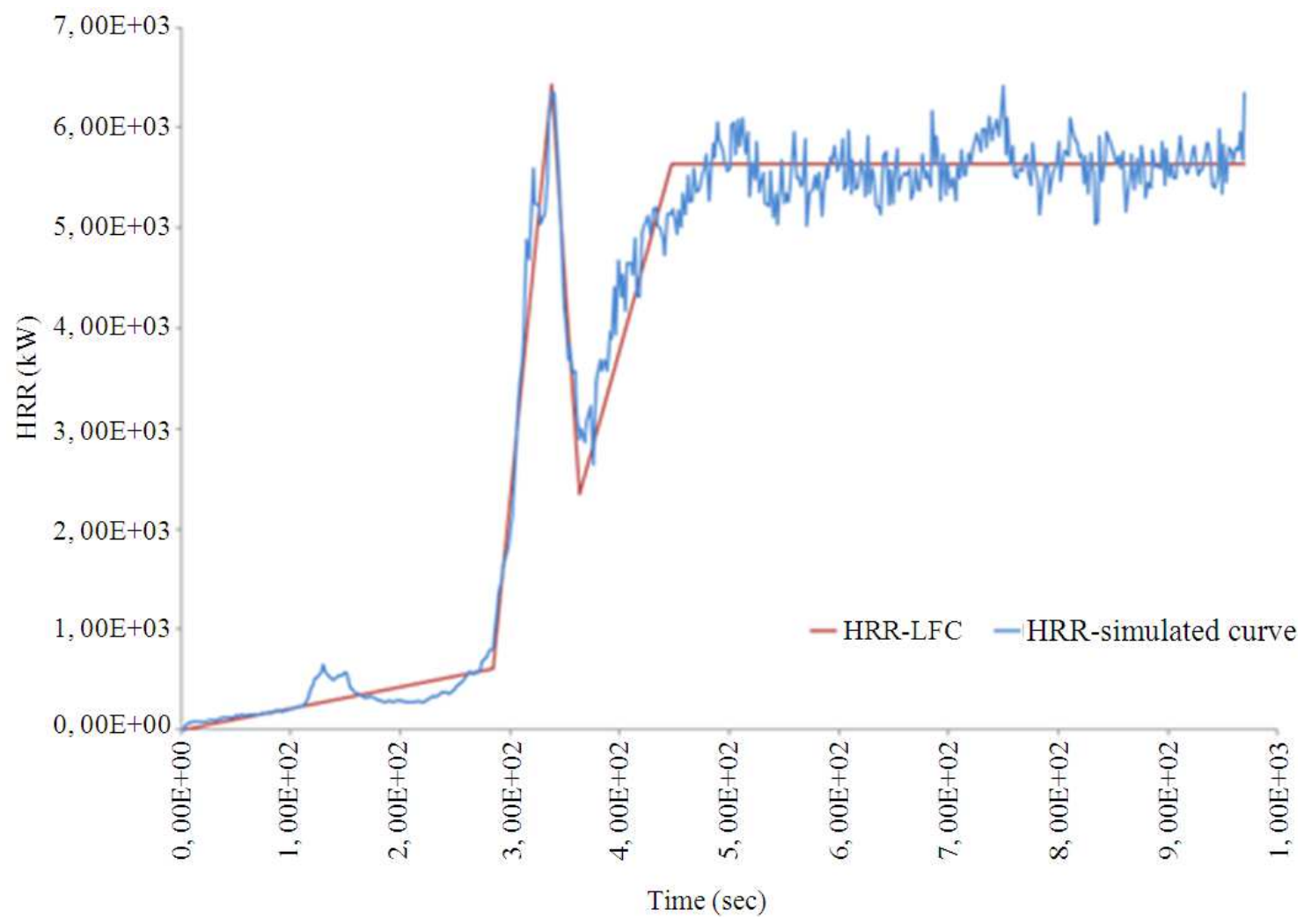

Fig. 8. Comparison between HRR Simulated Curve and HRRLFC

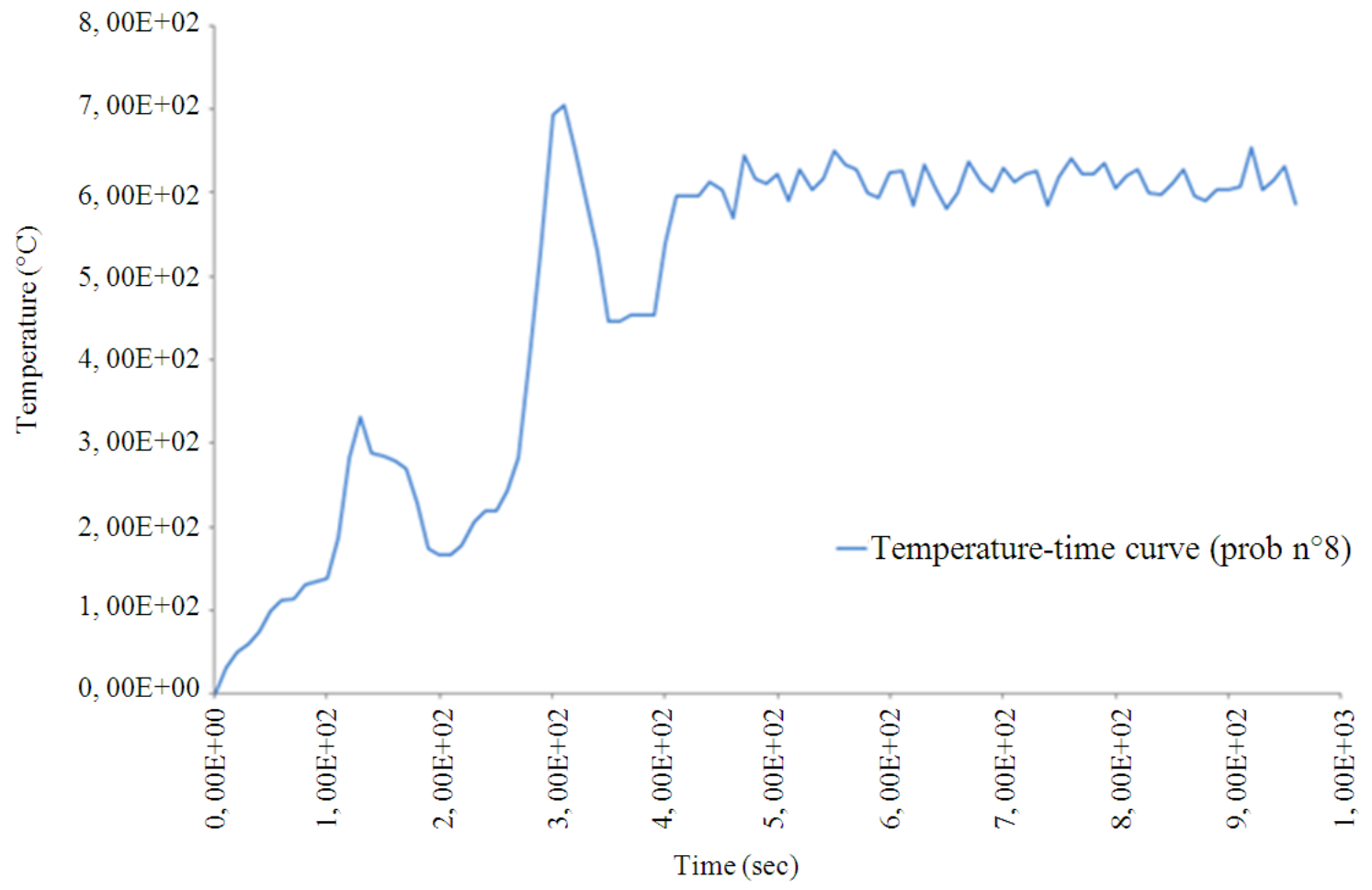

Fig. 9. Simulated temperature-time curve (measured values by probe No 8) 
The transmission of fire on other furniture of the room occur by thermal radiation.

\subsection{Simulation Results with Fire Natural Curve}

The fire simulation developed under the described conditions returns the following set of results:

- $\quad$ Simulated HRR curve (Fig. 8)

- Temperature-Time curve in the simulated domain, as measured by the probes (Fig. 9)

The trend of the function HRR highlights:

- A phase of ignition (incipient phase) from $0 \mathrm{~s}$ to about $280 \mathrm{~s}$

- A development phase (growth phase) until reaching a peak at about $320 \mathrm{~s}$ and $6 \mathrm{MW}$ of thermal power

- The achievement of flash point (fully developed phase) over about $300 \mathrm{~s}$

- A phase of decay due to the extinction of the combustible material, consisting of the initially primed mat

- A new phase of growth that activates at about $360 \mathrm{~s}$

- The achievement of a steady phase (plateau) of full development to about $460 \mathrm{~s}$ and 5.6 MW of thermal power maintained until the stop of the simulation
The Temperature-Time curve in the simulated domain has a trend alike to trend of HRR curve (Fig. 9) and in particular shows:

- A growth phase from $0 \mathrm{~s}$ to $410 \mathrm{~s}$ that highlights two peaks and two phases of growth, the first corresponding to primer $\left(130 \mathrm{~s}\right.$ and $\left.332^{\circ} \mathrm{C}\right)$ and subsequent extinction of the mat, the second corresponding to a flashover point $(300 \mathrm{~s}$ and $700^{\circ} \mathrm{C}$ ) and subsequent propagation of fire to the remaining furnishings

- A steady phase (Temperature equal to $600^{\circ} \mathrm{C}$ ) till the stop of simulation

In the simulated domain the trend of temperature shows, as expected, detected maximum values at the ceiling. Indeed the detected value of temperature (probe n. 8 located in midpoint of ceiling), highlights a similar trend as the HRR curve (incipient phase, growth phase, fully developed phase and decay phase) according to the stratification of hot fumes in the top of the domain.

The remaining probes showed a significant increase of temperature when the combustible objects nearby burn because of flash-over between $280 \mathrm{~s}$ and $320 \mathrm{~s}$ (Fig. 10).

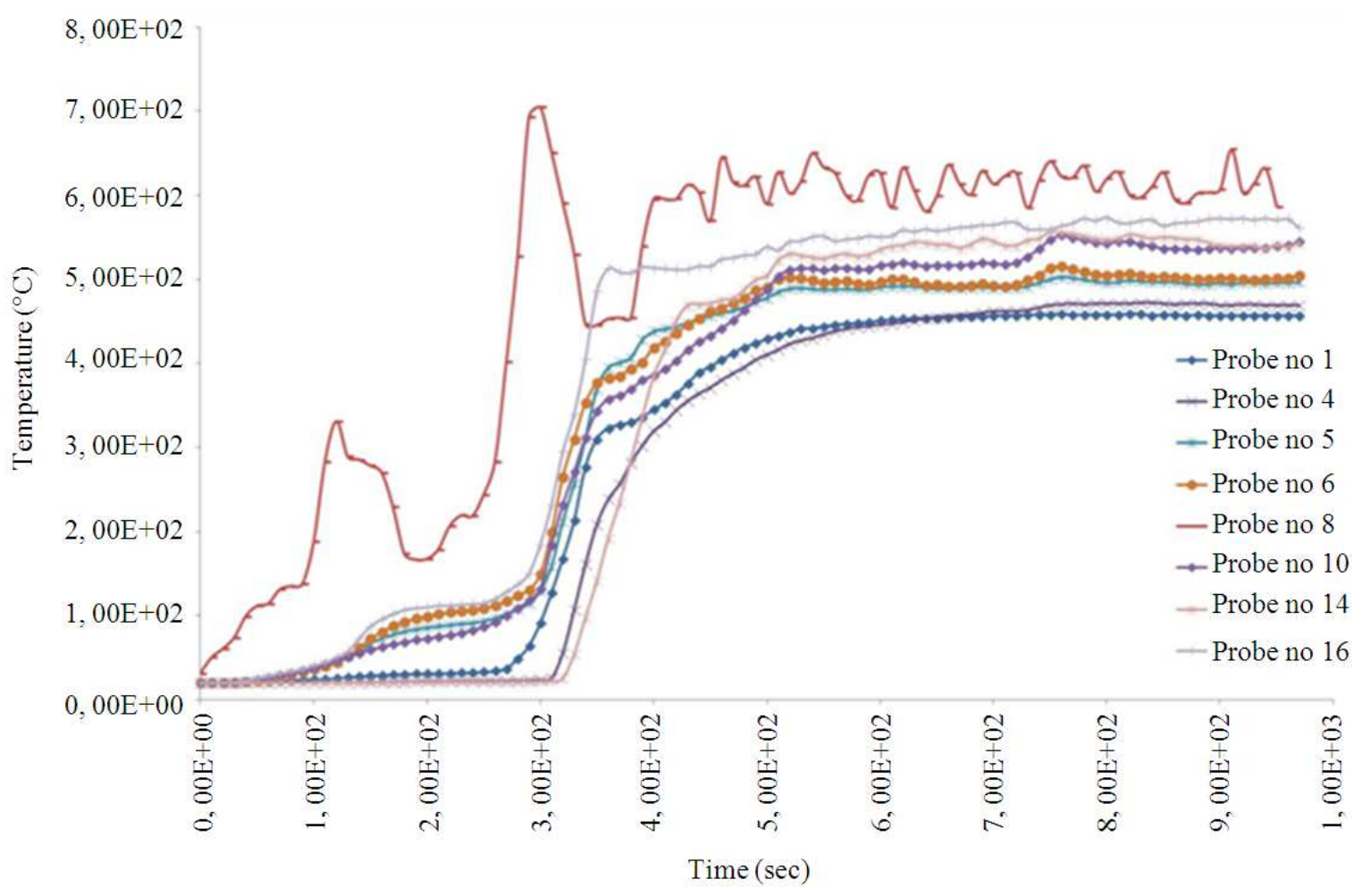

Fig. 10. Simulated temperature-time Curve (measured values by probes) 

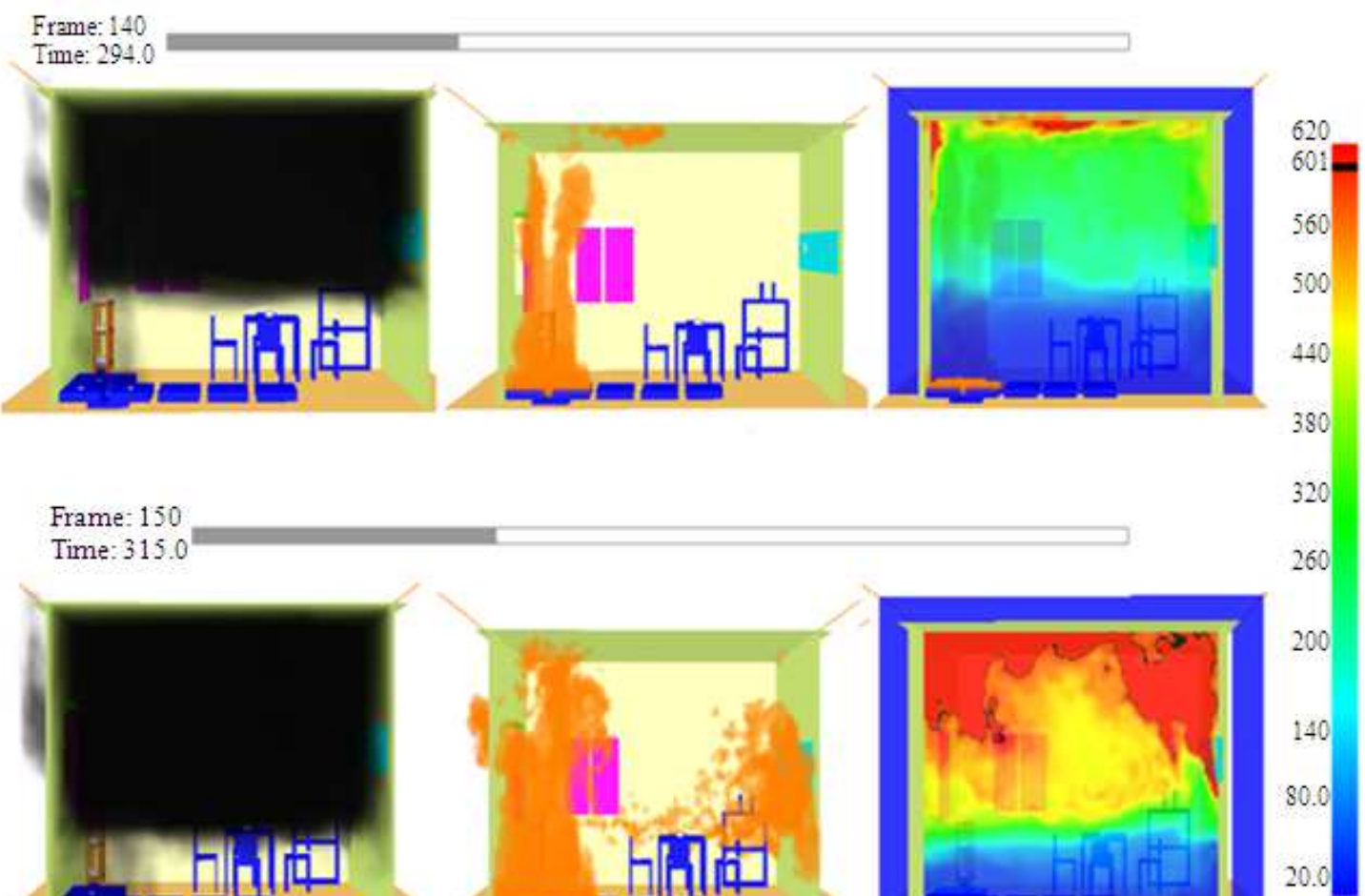

Frame: 150

Time: 315.0

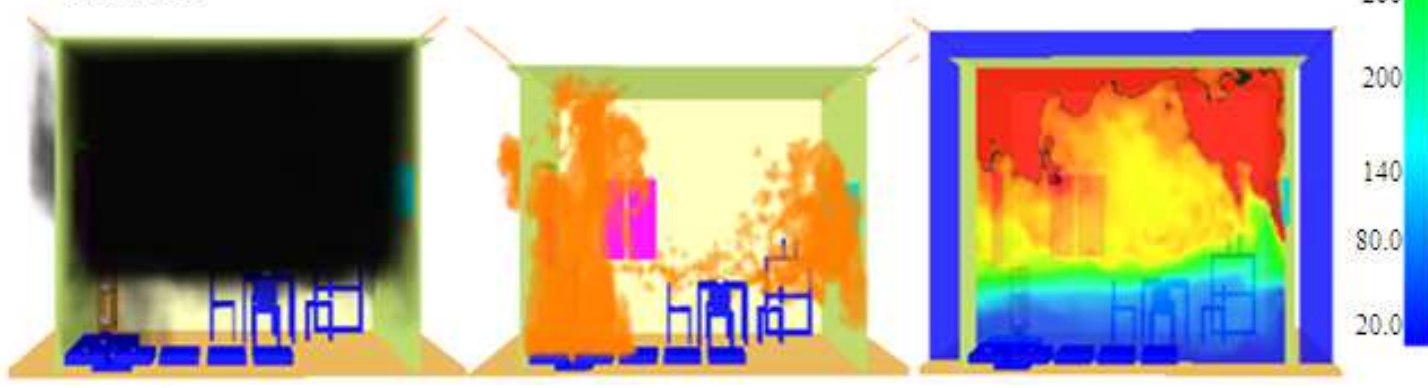

Fig. 11. Visual assessment of flashover point

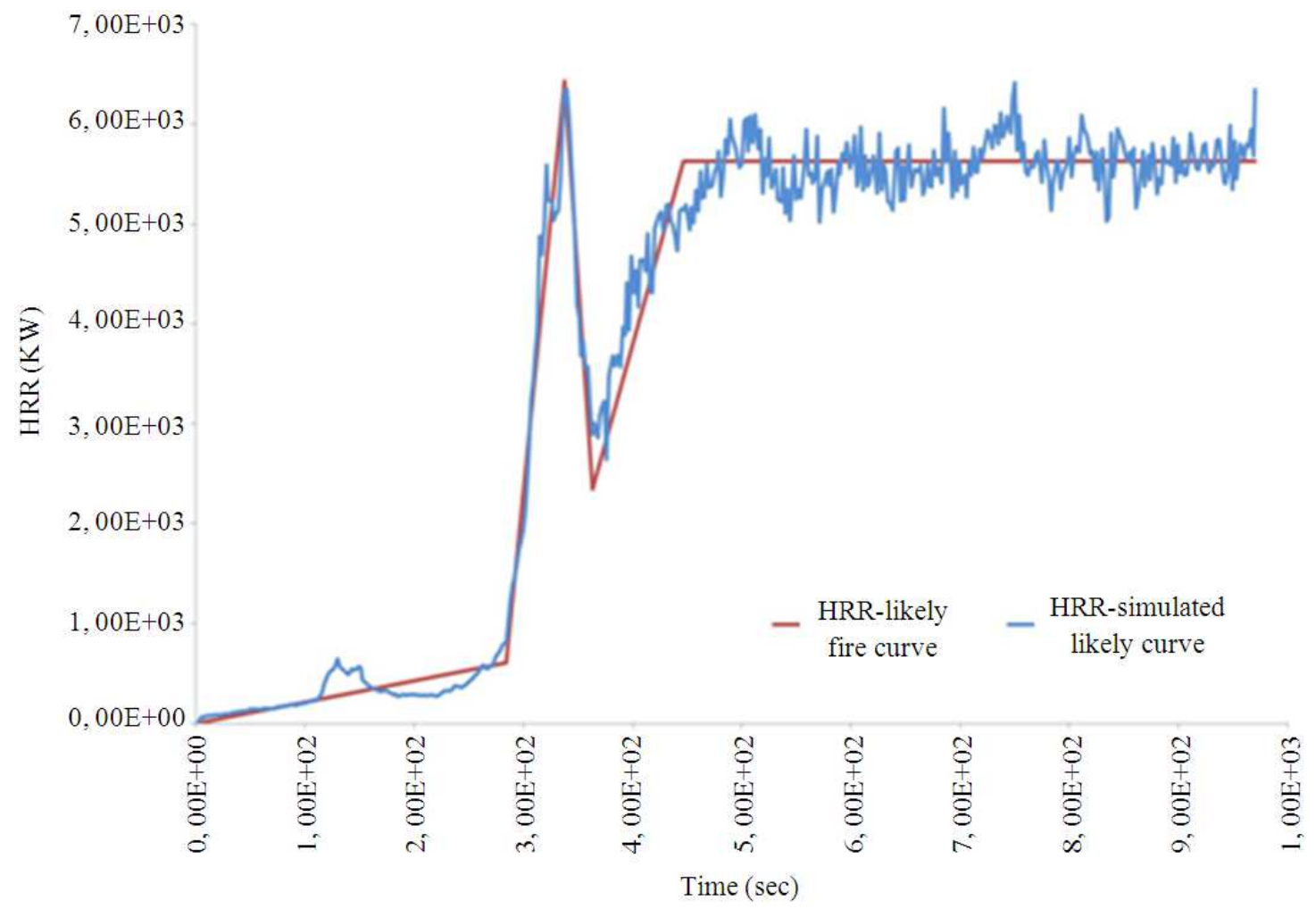

Fig. 12. Linearization of simulated HRRLFC 
The maximum value of temperature, recorded by probe located on the ceiling of the room, is approximately $700^{\circ} \mathrm{C}$, whereas the remaining probes have measured maximum value of temperature between $450^{\circ} \mathrm{C}$ and $550^{\circ} \mathrm{C}$.

The flashover point is identified by visual assessment, as proposed by Francis and Chen (2012) (Observable properties of flashover) and Babrauskas et al. (2003) and shown in Fig. 11.

The selected images highlight the variation of the field of visibility, temperature and heat flux in the time between $294 \mathrm{~s}$ and $315 \mathrm{~s}$ and show sudden lowering of neutral plane below the average height of the openings, the spread of the flames to the furniture far from primer and the lowering of the isotherm $600^{\circ} \mathrm{C}$ of the height of survival (conventionally placed at $2 \mathrm{~m}$ ).

Both The estimated quantitative value and the evidences represented in Fig. 11 confirm the hypothesis that at time equal to $294 \mathrm{~s}$ conditions of flashover point instantly occur.

The simulated HRR curve was linearized to obtain a HRR curve inserted as input in the FDS-EVAC solver for the large scale simulation of structure:
- The discretized function is called Likely Fire Curve (LFC)

- Per each segment $\mathrm{HRR}_{\mathrm{LFC}}$ is iso-integral curve compared with the fire curve (Fig. 12)

Table 1 shows the values of thermal energy, integrated on line segment and limit point (HRR, t) of the polyline $\mathrm{HRR}_{\mathrm{LFC}}$.

The achieved result confirms the representativeness of the analyzed case: it was found that the $\mathrm{HRR}_{\mathrm{LFC}}$ shows a coefficient of growth $(\alpha)$ correspond to what proposed by Eurocode (2004), where it is suggested, regarding to fire simulations with natural curve in school building, the adoption of a medium type coefficient of growth and $\mathrm{t}_{\alpha}$ equal to $300 \mathrm{~s}$.

The natural curve, derived by the simulation, shows an ignition time " $\mathrm{t}_{\mathrm{g}}$ " (up to the achievement of thermal power value equal to $1 \mathrm{MW}$ ) equal to about $290 \mathrm{~s}$ from which it $\alpha$ coefficient is derived Equation (4):

$$
\alpha=\left(\frac{1 \mathrm{MW}}{\mathrm{t}_{\mathrm{g}}{ }^{2}}\right)=\left(\frac{1000}{290^{2}}\right)=0.01189 \mathrm{KW} / \mathrm{s}^{2}
$$

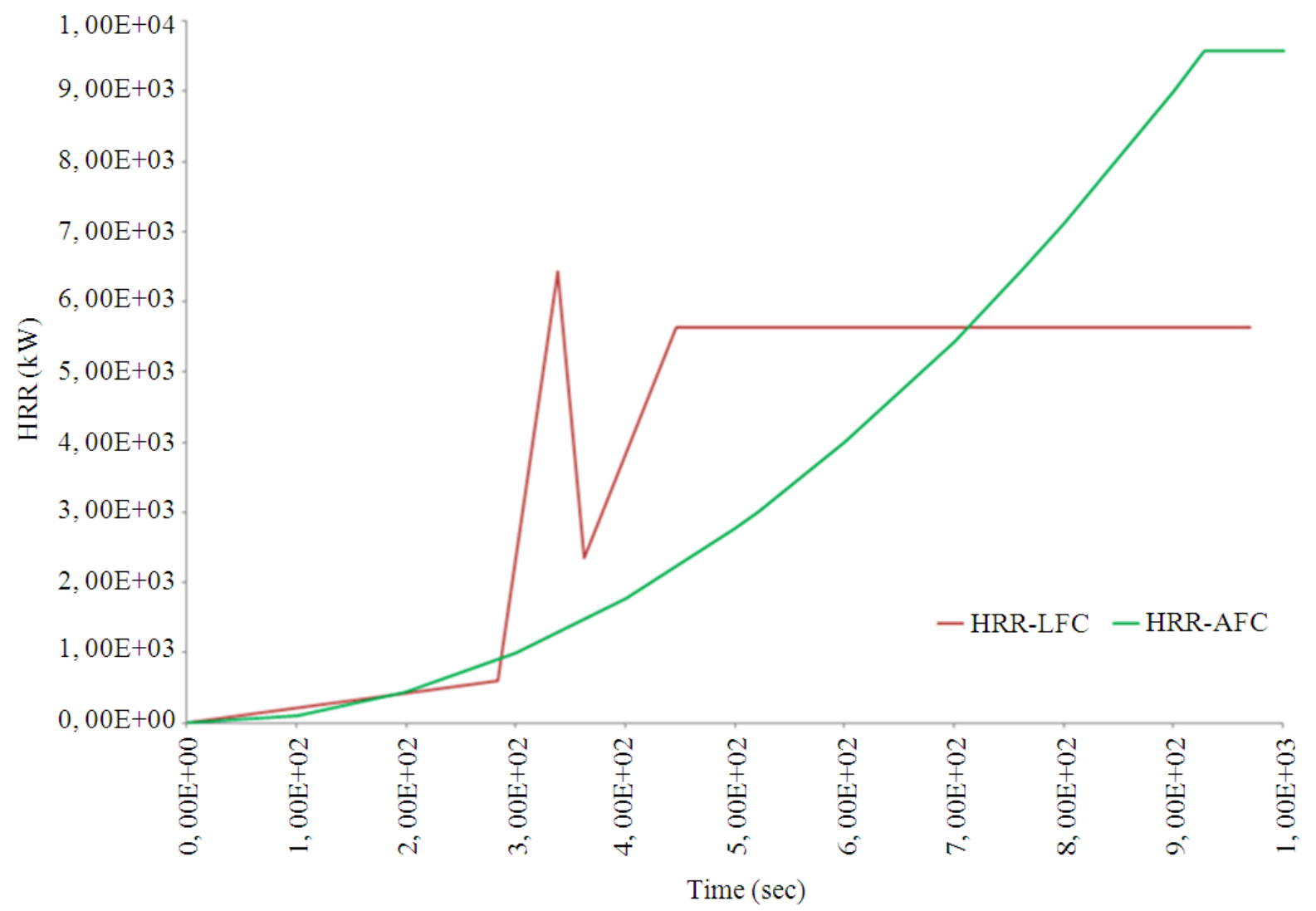

Fig. 13. Comparative analysis between HRRLFC curve and HRRAFC 


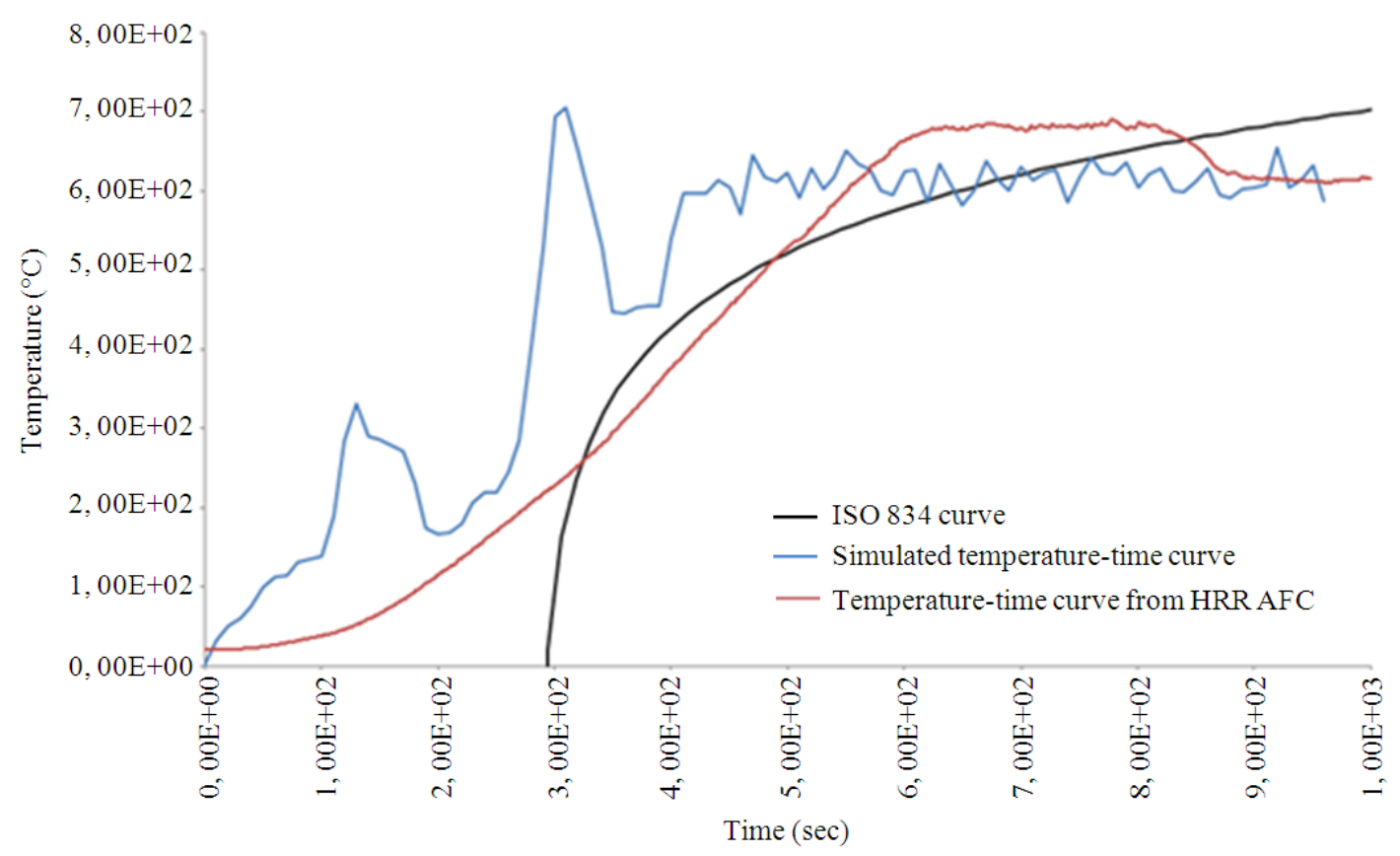

Fig. 14. Comparison between Temperature-Time Curves from HRRLFC, HRRAFC, HRRISO

Table 1. Shows the values of thermal energy, integrated on line segment and limit point (HRR, $t$ ) of the polyline HRRLFC

\begin{tabular}{|c|c|c|c|}
\hline$(\mathrm{KW})$ & Released thermal energy $(\mathrm{Kj})$ & Time (S) & HRR \\
\hline AREAN $^{\circ} 1$ & 86631, & 0 & 0 \\
\hline $\mathrm{AREAN}^{\circ} 1$ & 192210 & 284 & 610 \\
\hline AREAN $^{\circ} 1$ & 112475 & 338 & 6429 \\
\hline AREAN $^{\circ} 1$ & 646195 & 363 & 2350 \\
\hline AREAN¹ & 2636900 & 447 & 5630 \\
\hline Total AREA & 3674411,24 & 970 & 5630 \\
\hline
\end{tabular}

The value is substantially the same as that recommended by the reference standard for fires of classrooms in medium type coefficient of growth equal to:

$$
\alpha_{\mathrm{m}}=0.01111 \mathrm{KW} / \mathrm{s}^{2}
$$

With a difference of about $7 \%$.

\subsection{HRRLFC Vs HRRAFC, Temperature-time Likely Curve Vs Temperature-time analytical curve and Temperature-time Likely Curve Vs ISO 834 Curve}

The comparative analysis between the $H_{R R} R_{L F C}$ curve and $\mathrm{HRR}_{\mathrm{AFC}}$ highlights, following the phase of ignition, a significant deviation of trend: the $\mathrm{HRR}_{\mathrm{AFC}}$, calculated according to Thomas's method, shows a continuous increasing of trend and the achievement of fully developed phase, with maximum thermal power exceeding the $\mathrm{HRR}_{\mathrm{LFC}}$ value, in a longer time interval compared to the $\mathrm{HRR}_{\mathrm{LFC}}$ function (Fig. 13).
Similarly, a comparison between the temperatures recorded by the thermocouples in the event of likely fire $\left(H R R_{L F C}\right)$, in the event of analytical curve $\left(\mathrm{HRR}_{\mathrm{AFC}}\right)$ and in the event of the ISO-834 (HRR $\left.\mathrm{HSO}_{\mathrm{ISO}}\right)$ curve is introduced (Fig. 14).

The ISO 834 curve is defined from flashover point, obtained by simulation in $\S 6.0$ and equal to $294 \mathrm{~s}$.

The comparison between three curves is based on Ingberg's equivalence criterion Ingberg (1928), which proposes the concept of equivalent time according to which are considered of equal hazard two fires that, defined minimum temperature of reference, are characterized by equal subtended areas (The equivalence between areas is given starting from a minimum temperature of reference placed $\left(60^{\circ} \mathrm{C}\right)$ according to BSI (2004) and consistently in order to verify the "limit state of rescue" of exposed, according with the general theory of compliance).

The calculation of equivalent time is the area under the $H_{R R} R_{L F C}$ curve; the first comparison is proposed with the $H_{R R} R_{A F C}$ curve, the second is with the $H_{R R}$ Iso curve. 
Table 2. Summary of the results of comparison between the curves of fire

\begin{tabular}{lll}
\hline Referential time & Equivalent time & \\
LFC [s] & ISO 834 Curve [s] & $\Delta \mathrm{t}$ \\
960 & 1089 & 130.5 \\
Referential time & Equivalent time & \\
LFC [s] & Analytical Curve [s] & $\Delta \mathrm{t}$ \\
960 & 1064 & 98 \\
\hline
\end{tabular}

The $H_{R R} R_{L F C}$ curve shows an equivalent time of 1089 sec with an intersection at about $700 \mathrm{sec}$, the $\mathrm{HRR}_{\mathrm{AFC}}$ has an equivalent time of $1064 \mathrm{sec}$ with an intersection at about $600 \mathrm{sec}$.

This confirms, according to previously comparison between the HRR curves, a greater severity of the phenomenon with the simulated likely fire curve than using both analytical and ISO 834 curves in the initial phase of fire (Table 2).

\section{CONCLUSION}

The result growth factor suggests that Fire Likely Curve can be considered typical of the simulated room, according to provisions of rules.

The comparative analysis between HRR Curves (Likely, analytical and ISO) and Temperature-time curves suggests that:

- The simulated functions from nominal curve show the common trend to undervalue the hazard of fire compared with the simulation of natural fire during ignition and growth phases, particularly at the time $(720 \mathrm{~s})$ that $\mathrm{HRR}_{\mathrm{AFC}}$ and $\mathrm{HRR}_{\mathrm{LFC}}$ curves intersect

- The greater thermal power of $H_{R R} R_{L F C}$ in the initial phase of fire means that the total thermal radiation, developed by the two curves, is equivalent at time equal to $1005 \mathrm{~s}$

This difference is due to the fact that $\mathrm{HRR}_{\mathrm{AFC}} \mathrm{AT}$ the $\mathrm{HRR}_{\max }$ value depends both on the geometry of the room and ventilation openings: the combustible material present in the compartment corresponds to total energy load equally distributed on the surface of the room, not considering, therefore, actual layout of furniture (relative distance between primer and remaining combustible materials).

The analytical curve of fire can therefore constitute condition of thermal stress for safety reasons for the structural test; whereas, the phenomenon of fire, described by $\mathrm{HRR}_{\mathrm{LFC}}$, presents more marked hazard for a time interval that considers, typically, the activation of self-rescue.

In the specific case the severity of conditions resulting from application of the $H R R_{L F C}$ is higher than those generated with established approaches of fire safety engineering (analytical curve and ISO 834 curve), suggesting the opportunity, for the specific purpose, of verifying the safety of exposed.

\section{REFERENCES}

Babrauskas, V., 2008. Heat Release Rates. In: The SFPE Handbook of Fire Protection Engineering, Beyler, C.L., R.L.P. Custer, W.D. Walton, J.M. Watts Jr and D. Drysdale et al. (Eds.), National Fire Protection Association, pp: 3-1-3-37.

Babrauskas, V., R.D. Peacock and P.A. Reneke, 2003. Defining flashover for fire hazard calculations: Part II.

BSI, 2004. The application of fire safety engineering principles to fire safety design of buildings: Part 6: Human factors: Life safety strategies: Occupant evacuation, behaviour and condition (sub-system 6). 1st Edn., British Standards Institution, London, pp: 20.

Eurocode, 2004. Actions on structures Part 1-2: General actions-Actions on structures exposed to fireSection 4

Francis, J. and A.P. Chen, 2012. Observable characteristics of flashover.

Ingberg, S.H., 1928. Test of the severity of building fires. Natl. Fire Protect. Q., 22: 28-32.

ISO, 1999a. ISO/TR 13387-2:1999(E) Fire Safety Engineering-Part 2: Design fire scenarios and design fires. Technical Report. International Organization for Standardization, Geneva.

ISO, 1999b. ISO/TR 13387-4:1999 Fire safety engineering -- Part 4: Initiation and development of fire and generation of fire effluents. Technical Report. International Organization for Standardization, Geneva.

McGrattan, K., S. Hostikka, J. Floyd, H. Baum and R. Rehm, 2007. Fire Dynamics Simulator (Version 5) Technical Reference Guide. NIST Special Publication 1018-5.

Richard, D. P., P.A. Reneke, R.W. Bukowski and V. Babrauskas, 1999. Defining flashover for fire hazard calculations. Fire Safety J., 32: 331-345.

SFPE, 2002. SFPE Handbook of fire Protection Engineering. 3rd Edn., NFPA, National Fire Protection Association, Quincy, ISBN-10: 0877654514, pp: 1000. 